\title{
Gene Expression of ABC Proteins in Hepatocellular Carcinoma, Perineoplastic Tissue, and Liver Diseases
}

\author{
Serena Bonin, ${ }^{1}$ Lorella Pascolo, ${ }^{2}$ Lory S. Crocé, ${ }^{2}$ Giorgio Stanta, ${ }^{1}$ and Claudio Tiribelli ${ }^{2}$ \\ ${ }^{1}$ Department of Clinical, Morphological and Technological Sciences, University of Trieste, and ICGEB \\ ${ }^{2}$ CSF and Department of BBCM, University of Trieste, Trieste, Italy \\ Accepted May 30, 2002
}

\begin{abstract}
Background: The development of hepatocellular carcinoma (HCC) is a frequent event during the natural history of cirrhosis. Effective treatment is, however, hampered by drug resistance related to the expression of multidrug resistance (MDR) proteins belonging to the $\mathrm{ABC}$ family transporters. Studying expression of genes coding for these proteins may help to explain the potential sensitivity of HCC to chemotherapy.

Material and Methods: The expression of MRP1, MRP2, $M R P 3, M D R 1$, and $M D R 3$ was investigated by quantitative RT-PCR analyses in paraffin-embedded tissues obtained from 9 cases of HCC, 16 cases of cirrhosis, 10 cases of chronic extrahepatic cholestasis, and 16 cases of normal liver. In HCC cases, gene expression was assessed both in neoplastic and perineoplastic tissue after microscopically assisted microdissection.
\end{abstract}

Results: MRP1 was significantly and similarly overexpressed in HCC and perineoplastic tissue. MRP2 and MDRl were also increased in HCC, but the level of expression did not correlate with that of perineoplastic tissue. The level of expression was either reduced or normal in cirrhotic liver and during chronic cholestasis. Expression of $M D R 3$ was unchanged in all conditions investigated.

Conclusions: The genetic expression of multi-drug resistance proteins, in particular $M R P 1, M R P 2$, and $M D R 1$, is increased during HCC. In the case of MRP1, the extent of expression is similar in neoplastic and perineoplastic tissue, but this is not the case for MRP2 and MDR1. The assessment of $\mathrm{ABC}$ protein expression pattern may provide important information for the diagnosis and treatment of HCC.

\section{Introduction}

Liver cirrhosis is a common disease, been detected in more that $1 \%$ of the general population (1-3). Hepatocellular carcinoma (HCC) is a frequent complication in the natural history of advanced chronic liver disease. It has been calculated that $3-5 \%$ of cases of cirrhosis evolve in HCC per year $(4,5)$. In addition to an early diagnosis of this life-threatening condition, several protocols have been suggested in the treatment of HCC (6-9). Among the others, including surgery, chemotherapy has been long described as a tool to reduce the growth of HCC and improve life expectancy of patients with this disorder (10).

A great limitation in the treatment of HCC is the development of resistance to multiple drugs used in chemotherapy, especially doxorubicin. Treatment with one specific anticancer drug often results in cross-resistance against a broad range of structurally unrelated drugs. This phenomenon is known as multidrug resistance (MDR). It was recently discovered that some ATP-dependent transporters belonging to

Correspondence and reprint requests should be addressed to: Claudio Tiribelli, MD PhD, CSF and Department BBCM, University of Trieste, Via Giorgeri 1, 34127 Trieste, Italy. Phone: +39-040-399 4927; fax: +39-040-399 4924;

e-mail: liver@fmc.units.it the $\mathrm{ABC}$ protein family play a central role in the treatment refractoriness and the members most involved are those belonging to $\mathrm{ABCB}$ (MDR) and $\mathrm{ABCC}$ (MRP) subfamilies (11). It had been long believed that the expression of the MDRl gene, encoding for a 170-kDa glycoprotein (MDR l or P-gp), was the exclusive mechanism of multidrug resistance observed exposing tumors to anthracyclines, Vinca alkaloids, taxanes, and other agents (12). This ATP-dependent transporter was discovered to protect tumors by sequestrating cytotoxic agents intracellularly or pumping them out of the cells. In 1992, Cole et al. (13) described the second major $\mathrm{ABC}$ transporter involved in MDR: the MDR-associated protein (MRP1). This protein, structurally different from P-gp (15\% amino acid homology), is present in the main organs and maximally in epithelial tissues (14). Its expression altered neoplastic proliferation with variable correlation to malignancy (15). The finding that also MRPI confers a MDR phenotype to tumor cells was of great help in the understanding the molecular bases of MDR. In the recent past, the advance in the knowledge of the functions of $\mathrm{ABC}$ proteins points to new targets to be investigated together with MRPI and MDRl. Understanding the role of other homologs to MDR I and MRPI is necessary to allow better clinical and therapeutic prognosis of the patient. The ABCC subfamily members as MRP2 and MRP3, together with 
MDR3 of the ABCB subclass, seem the more promising. MDR and MRP proteins are normally expressed in liver and they are the main proteins responsible for bile formation. The $\mathrm{ABC}$ proteins expressed on the canalicular membrane of the hepatocytes regulate the biliary excretion of cholephilic organic ions, whereas those basolaterally located act to limit cellular accumulation by pumping substrates back into the blood (16). MRP2 is a canalicular transporter that mediates biliary excretion of conjugated bilirubin and other different organic substrates (17); the role of MRP1 and MRP3, both expressed basolaterally, is still partially unknown. MDR1 and MDR3 are two close genes probably generated by duplication of an ancestor gene, but they codify for two canalicular proteins with different transport functions: MDR 1 is a multispecific transporter of organic cations, and MDR3 is the phospholipids transporter affected in PFIC3 syndrome (18). Although there is a great difference in terms of substrate specificity, it has been demonstrated that MDR and MRP proteins are all able to confer MDR and accordingly, it would be of clinical interest and therapeutic significance to understand the genetic expression of members of the two $A B C$ subfamilies in HCC and perineoplastic tissues, and to compare their expression with that observed in other chronic liver disorders not complicated by HCC. To this end, we investigated the genetic expression of three MRPs (MRP1, 2 and 3) and two MDR proteins (MDR 1 and MDR3) in HCC tissue as well as in the perineoplastic, nonneoplastic liver, and compared the expression with that found in cirrhotic subjects, in patient with extrahepatic cholestasis, and in subjects without liver disease. Data indicate that both MRP1 and MRP2 as well as $M D R 1$ are significantly overexpressed in HCC and perineoplastic samples.

\section{Material and Methods}

Materials and Patients

Tissues were obtained from the Department of Pathology of the University of Trieste. The study included 9 cases of hepatocellular carcinomas, 16 cases of cirrhosis, and 10 cases of extrahepatic cholestasis; 16 normal autoptic livers were used as control. The case study was composed of 19 women and 32 men. The characteristics of the cases examined are reported in Table 1. Patients were randomly selected (random procedure of SPSS package, SPSS Inc., Chicago, IL, USA) on the basis of autoptic records from January 1, 1999 through June 30, 2000. Medical records of each patient were available in the data base of the medical school of the University of Trieste. All HCC cases showed a single lesion with a diameter ranging from 4-6 cm; a single cycle of treatment of chemoembolization with doxorubicin $(50 \mathrm{mg})$ was performed in five of nine cases of HCC. $\mathrm{HCV}$ infection was recorded in four of nine HCC cases $(45 \%)$, and HBV infection or inadequate alcohol consumption (greater that $60 \mathrm{~g} /$ day) (19) was found in three $(33 \%)$ and two $(22 \%)$ cases, respectively. Cirrhosis was associated with HCV infection in eight cases $(50 \%)$ whereas HBV and alcohol intake greater that $60 \mathrm{~g} /$ day was recorded in two $(12 \%)$ and six $(38 \%)$ cases, respectively. Normal cases were defined as patients who died with causes different from liver disease (cardiovascular accident in the vast majority) and where gross and histologic examination of liver showed no lesions. In these subjects neither HCV and HBV nor increased alcohol consumption was recorded. The protocol of the study was approved by the ethical committee of the University of Trieste.

Tissues were fixed in $10 \%$ buffered formalin, and the paraffin-embedded tissue was cut in sections $(10 \mu \mathrm{m})$ and immediately processed. In the case of HCC, the tissue was examined by one of us (G.S.) on microscopy and the carcinoma tissue carefully dissected from the perineoplastic tissue. The two portions (carcinoma and perineoplastic tissue) of morphologically defined disease were analyzed separately. To avoid contamination during the cutting of paraffin blocks, the microtome blade was cleaned (five times) after every sample with nonhazardous xylene substitute.

\section{RNA Extraction}

RNA was extracted from $10-\mu \mathrm{m}$ sections of paraffinembedded tissues as previously reported $(20,21)$. In each case, 10 sections were cut with standard microtome. In the nine cases of hepatocellular carcinoma, the samples of tumor and perineoplastic tissues were analyzed separately. To obtain tissue for RNA

Table 1. Patient demographics

\begin{tabular}{|c|c|c|c|c|c|}
\hline Disease & $\begin{array}{c}\text { Average } \\
\text { Age (Years) }\end{array}$ & $\begin{array}{c}\text { Standard } \\
\text { Deviation }\end{array}$ & $\begin{array}{c}95^{\text {th }} \\
\text { Percentile }\end{array}$ & $\begin{array}{c}\text { Female } \\
(n)\end{array}$ & $\begin{array}{c}\text { Male } \\
(n)\end{array}$ \\
\hline $\mathrm{HCC}$ & 63.4 & 8.63 & 72.2 & 1 & 8 \\
\hline Cirrhosis & 65.9 & 12.0 & 84.75 & 4 & 12 \\
\hline Cholestasis & 73.5 & 10.6 & 91.25 & 4 & 6 \\
\hline Normal & 78.1 & 9.92 & 93.25 & 10 & 6 \\
\hline
\end{tabular}


extraction, deparaffinization was performed in xylene (twice) followed by ethanol washing (two times) to remove the organic solvent. Purified RNA was obtained by protein digestion with high concentration $(6 \mathrm{mg} / \mathrm{ml})$ of proteinase $\mathrm{K}$ in the presence of $1 \mathrm{M}$ of guanidine thiocyanate (21). An extraction with phenol- $\mathrm{H}_{2} \mathrm{O} /$ chloroform $(70: 30 \mathrm{v} / \mathrm{v})$ was performed to purify RNA from proteinase $\mathrm{K}$ and proteolysis residues. Extracted RNA was concentrated by isopropanol precipitation by using glycogen as precipitation carrier (20).

\section{Quantitative RT-PCR Analysis}

Quantitative PCR for RNA in paraffin-embedded tissues should be performed by relative quantitation in comparison with the level of mRNA coding for a housekeeping gene ( $\beta$-Actin). Competitive RT-PCR is not possible in paraffin-embedded tissues because of the random level of RNA degradation. Accordingly, to compare results obtained from different samples, the results must be standardized with a factor calculated from the mean value of counts of the housekeeping PCR amplification. Relative quantitation of the different mRNA was achieved by transcription into cDNA and PCR amplification. The maximal length of the amplicon must be in the range of $100-120$ bases $(22,23)$. Amplification was performed in logarithm phase, when a linear correlation is present between the log of the initial quantity of RNA and the log of the quantity of amplified product. Amplification conditions were assessed for each gene analyzed. Repeated analyses using RNA from the same specimen were performed to obtain the intratest variability, which was found to be $\mathbf{8 - 9 \%}$ for each gene studied. For each analyzed gene, three oligonucleotides were synthesized (Table 2), two in mRNA sense and one in antisense orientation for reverse transcription. To avoid genomic DNA amplification, the first sense and the antisense oligonucleotides were selected in two successive exons of the studied gene. The second sense oligonucleotide spanned over two exon junctions and was used as a probe for the amplified product.

The analyzed $\mathrm{ABC}$ transporters were MRP1 (MDR-associated protein 1, ABCC1, GeneBank NM 004996), MRP2 (ABCC2, GeneBank NM_000392), MRP3 (ABCC3, 000392 NM_003786), MDR1 (ABCB1, GeneBank NM_000927), and MDR3 (ABCB4 GeneBank NM_00043).

RNA concentration was assessed spectrophotometrically at $260 \mathrm{~nm}$. Reverse transcription was performed using AMV reverse transcriptase (Promega, Madison, WI, USA) and sequence-specific antisense primer. Reverse transcription was performed in $10 \mu \mathrm{l}$ final volume containing $50 \mathrm{mM}$ Tris- $\mathrm{HCl}, \mathrm{pH} 8.3$, $50 \mathrm{mM} \mathrm{KCl}, 8 \mathrm{mM} \mathrm{MgCl}, 0.25 \mathrm{mM}$ dNTPs, 4 units of RNase Inhibitor (Ambion, Austin, TX, USA), 2 units of AMV reverse transcriptase (Promega), 15 pmole of antisense primer, and the proper amount of RNA. The reaction proceeded at $42^{\circ} \mathrm{C}$ for $60 \mathrm{~min}$. Amplification was performed by adding $40 \mu \mathrm{l}$ of $10 \mathrm{mM}$ Tris- $\mathrm{HCl}, \mathrm{pH} 8.3,55 \mathrm{mM} \mathrm{KCl}, 15$ pmole of upstream primer, and 1.2 units of Taq DNA Polymerase (Amersham Biosciences, Uppsala, Sweden). Samples solutions were denatured for $3 \mathrm{~min}$ at $95^{\circ} \mathrm{C}$, subjected to five cycles of $1 \mathrm{~min}$ at $95^{\circ} \mathrm{C}, 1 \mathrm{~min}$ at the annealing temperature and $1 \mathrm{~min}$ at $72^{\circ} \mathrm{C}$, followed

Table 2. Oligonucleotide sequences PCR and hybridization conditions

Oligonucleotide Sequence

$\beta$-Act up: 5'-AAG GCC AAC CGC GAG AAG ATG A-3' sense

$\beta$-Act dw: 5'-TGG ATA GCA ACG TAC ATG GCT G-3' antisense

$\beta$-Act Probe: $5^{\prime}$-CCC AGA TCA TGT TTG AGA CCT TCA ACA CCC-3' sense.

MDRl up: 5'-GAA ACC AAC TGT CAG TGT-3'

MDR 1 dw: 5'-AGC ATC ATG AGA GGA AGT-3'

MDR 1 up (probe): 5'-TCA ATG TTT CGC TAT TCA AAT TGG C-3' sense.

MDR3 up: 5'-ACA CGC GCG AGG TTC GAG-3'

MDR3 dw: 5'-TGC TGC TGA TGC CCA GTT-3'

MDR3 up (probe): 5'-GCT GAG ATG GAT CTT GAG GCG GCA-3'sense.

MRPl up: 5'-TGT TCT CGG AAA CCA TCC A-3'

MRPl dw: 5' -CAA TCA ACC CTG TGA TCC A-3'

MRPl up (probe): 5'-ACC CTA ATC CCT GCC CAG AGT CCA-3'

MRP2 up: 5'-CTG CCA TTC GAC ATG ACT-3'

MRP2 dw: 5' -TGT CCA GGT TCA CAT CTC-3'

MRP2 up (probe): 5'-GCA ATT TTG ACA AAG CCA TGC AGT-3' sense.

MRP3 up: 5'-TGG TGG GCC TTT CTG TGT-3'

MRP3 dw: 5'-CCT CTC CAC AGC CAC GAT-3'

MRP3 up (probe): 5' -TAC TCC TTG CAG GTG ACA TTT GCT-3' sense.

\section{Reaction Conditions}

RT, $10 \mathrm{ng}, \mathrm{Ta} 55^{\circ} \mathrm{C}, 40$ cycles, hybridization at $50^{\circ} \mathrm{C}$

$\mathrm{RT}, 125 \mathrm{ng}, \mathrm{Ta} 50^{\circ} \mathrm{C}, 45$ cycles, hybridization at $54^{\circ} \mathrm{C}$

$\mathrm{RT}, 125 \mathrm{ng}, \mathrm{Ta} 63^{\circ} \mathrm{C}, 45$ cycles, hybridization at $55^{\circ} \mathrm{C}$ with $4 \%$ formamide

RT, 50 ng, Ta $59^{\circ} \mathrm{C}, 45$ cycles, hybridization at $55^{\circ} \mathrm{C}$ with $4 \%$ formamide

$\mathrm{RT}, 120 \mathrm{ng}$, Ta $55^{\circ} \mathrm{C}, 45$ cycles, hybridization at $54^{\circ} \mathrm{C}$

RT, 100 ng, Ta $58^{\circ} \mathrm{C}, 45$ cycles, hybridization at $45^{\circ} \mathrm{C}$ with $7.5 \%$ formamide 
by a variable number of cycles of $30 \mathrm{sec}$ at $95^{\circ} \mathrm{C}$, $30 \mathrm{sec}$ at the annealing temperature, and $30 \mathrm{sec}$ at $72^{\circ} \mathrm{C}$.

The amplification products were tested by dot blot and probe hybridization. In dot blot, preparation $20 \mu \mathrm{l}$ of amplified material were denaturated for $10 \mathrm{~min}$ at $95^{\circ} \mathrm{C}$ and chilled on ice. After this step, $30 \mu \mathrm{l}$ of $20 \times$ saline sodium citrate (SSC) and $1 \mu \mathrm{l}$ of dye for dot blot were added to each sample. Specimens were spotted on a pre equilibrated Hybond $\mathrm{N}^{+}$ membrane (Amersham Biosciences) using a dot blot apparatus. Membrane was air dried and crosslinked twice in a UV-Strataliker (Stratagene, La Jolla, CA, USA). Radiolabeled probe was prepared by kinazation of internal oligonucleotide to the amplified sequence. Reaction was performed with $500 \mathrm{ng}$ of oligonucleotide using 10 units of polynucleotide kinase U (New England Biolabs Inc., Beverly, MA, USA) and $50 \mu \mathrm{Ci}$ of $\left[\gamma_{-}{ }^{32} \mathrm{P}\right]$ ATP (Amersham Biosciences) for $1 \mathrm{hr}$ at $37^{\circ} \mathrm{C}$. Labeled probe was then purified onto a G-25 Sephadex (Amersham Biosciences) minicolumn.

After prehybridization for $1 \mathrm{hr}$, the membranes were hybridized overnight at the proper temperature, in $6 \times$ SSC, $0.25 \%$ milk powder. Two washes in $6 \times$ SSC, $0.1 \%$ SDS at room temperature were then performed followed by two washes in $3 \times$ SSC, $0.1 \%$ SDS and two in $1 \times$ SSC, $0.1 \%$ SDS, the temperature by $10^{\circ} \mathrm{C}$ higher than the hybridization. Radioactivity of the membrane was detected by a Cyclon Storage Phosphor System (Packard Instrument, Meriden, CT, USA). The quantity of amplified material for each analyzed gene was expressed in digital light units (DLU).

\section{Statistical Analysis}

ANOVA was performed to assess the homogeneity of variance among groups for different genes. When the variance was homogeneous, Tukey's test (parametrical) was used and the Kruskal-Wallis test (nonparametrical) was employed for gene expression without homogeneous variance. Two-sided probability values of less than 0.05 were considered to indicate statistical significance. Statistical analyses were performed using the SPSS/PC software. The correlation between mRNA expression in neoplastic and perineoplastic tissues was assessed by linear correlation coefficient (correlation coefficient $r^{2}$ and two-sided $p$ value).

\section{Results}

The expression of the mRNA of five ABC transporters was assessed in HCC, perineoplastic tissue, cirrhosis, and extrahepatic cholestasis; liver without sign of liver disease was used as control.

\section{$M R P 1, M R P 2$, and MRP 3}

As shown in Figure 1A, MRP1 expression is significantly higher $(p<0.005)$ both in neoplastic and

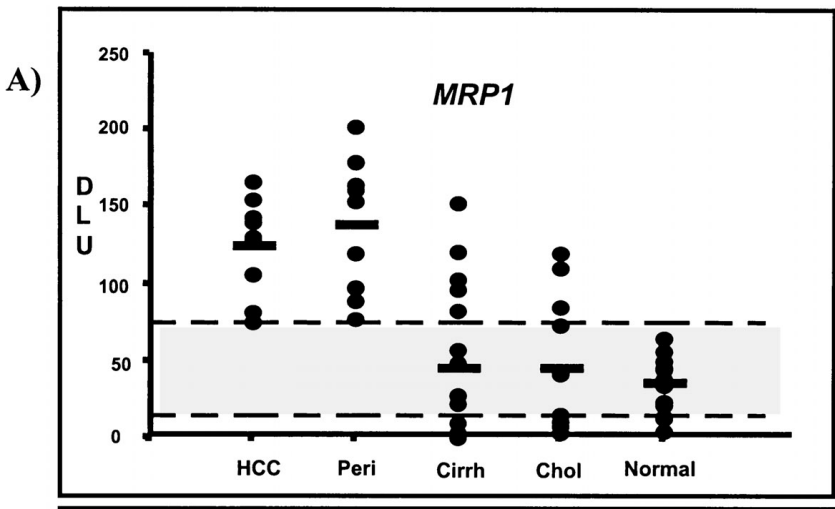

B)

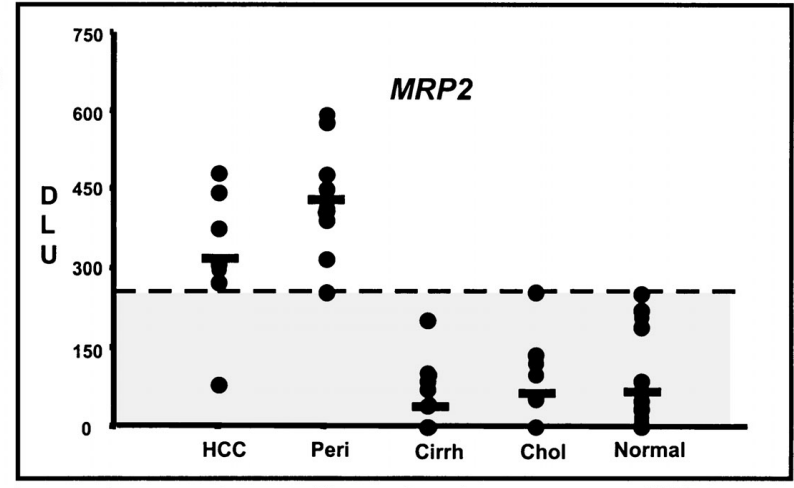

C)

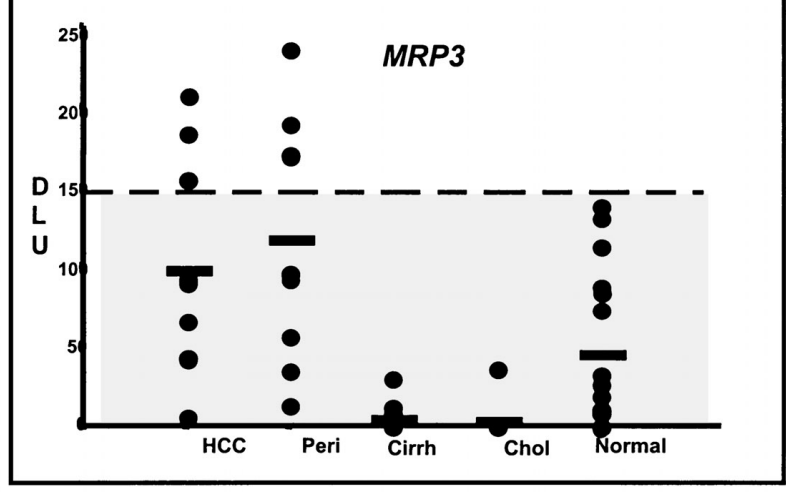

Fig. 1. mRNA expression level (in DLU) of the analyzed ABCC transporters in liver diseases. (A) MRP1. (B) MRP2. (C) MRP3. The mean value is indicated by a bar (-). The shadowed area represent the men value \pm 2 SD found in controls. A number of dots lower than the number of cases indicates overlapping of values. HCC, hepatocellular carcinoma; Peri, perineoplastic tissue; Cirrh, cirrhosis; Chol, cholestasis; Normal, control liver.

perineoplastic tissue; no difference was observed between the neoplastic and perineoplastic tissue. All samples analyzed were higher than the normal value calculated as the mean $\pm 2 \mathrm{SD}$ of the value found in control livers. The mRNA expression of $M R P 2$ was also significantly increased $(p<0.001)$ in neoplastic and even higher in perineoplastic lesions, although one case with HCC showed a value within the normal range (Fig. 1B). As for MRP1, no difference was observed in cirrhosis or cholestasis as compared to controls. On the contrary, as shown 
Figure 1C, MRP3 expression was increased in both neoplastic and perineoplastic tissue $(p<0.001)$, although the mean value fell within the normal range. MRP3 expression was, on the contrary, noticeably low in both cirrhosis and cholestasis; in the control group, a rather scattered distribution was observed.

\section{$M D R 1$ and $M D R 3$}

As shown in Figure 2A, and similarly to what was observed with MRP1, MDR1 expression was significantly higher $(p<0.005)$ in neoplastic and perineoplastic tissues. On the contrary, the expression was low, and similar to controls, in cirrhotic and cholestatic livers. As shown in Figure 2B, the expression of $M D R 3$ was fully comparable in the five groups and all the values, with the exception of a single case in neoplastic and perineoplastic tissues, fell within the normal range.

A)

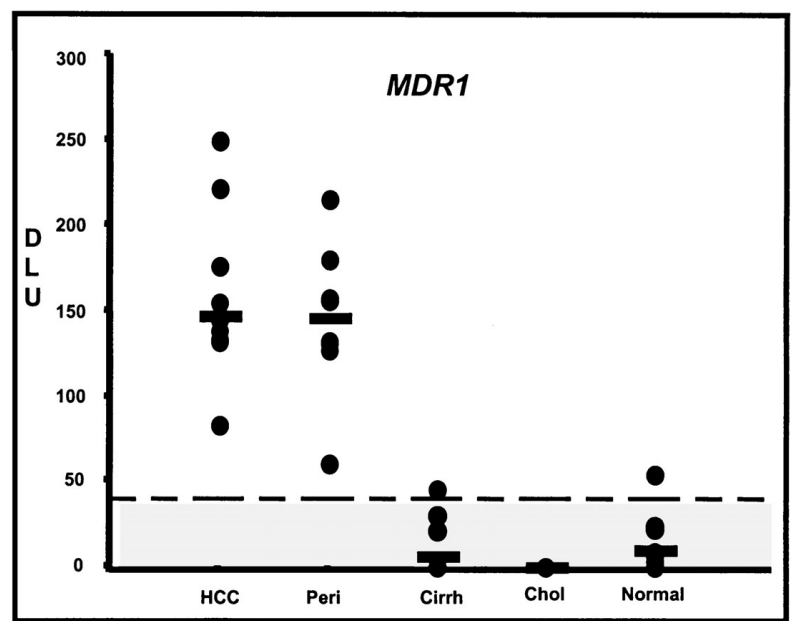

B)

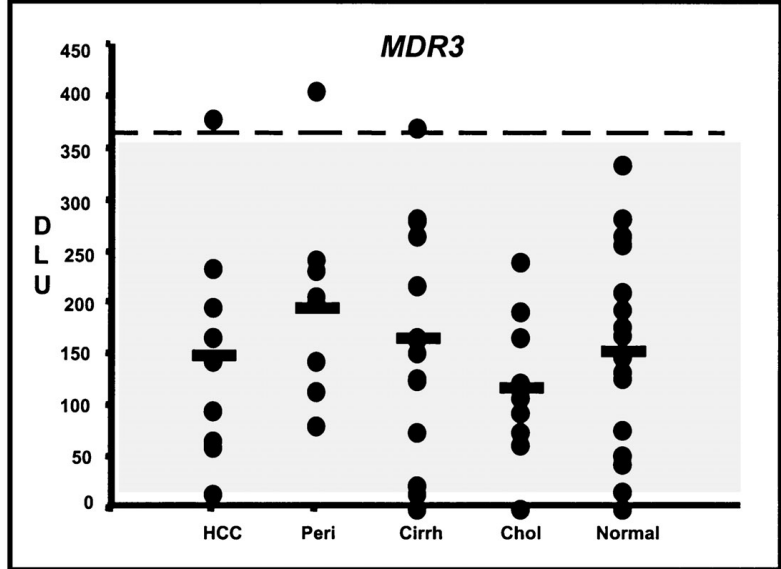

Fig. 2. mRNA expression level (in DLU) of the analyzed ABCB transporters in liver diseases. (A) MDR1. (B) MDR3. The mean value is indicated by a bar (-). The shadowed area represent the men value \pm 2 SD found in controls. A number of dots lower than the number of cases indicates overlapping of values. HCC, hepatocellular carcinoma; Peri, perineoplastic tissue; Cirrh, cirrhosis; Chol, cholestasis; Normal, control liver.
Correlation Between Gene Expression in Neoplastic and Perineoplastic Tissue

To investigate whether the variation observed in the expression of the different $\mathrm{ABC}$ transporters in neoplastic and perineoplastic tissue may be related, the mRNA level observed in the two samples was compared. As shown in Figure $3 \mathrm{~A}, M R P 1$ expression showed a liner, statistically significant $(p=0.028)$ correlation, indicating that a higher expression of $M R P 1$ in neoplastic tissue was associated with a similar higher expression in the surrounding perineoplastic tissue. This was not the case either for MRP2 and MRP3 (Figs. $3 \mathrm{~B}$ and $3 \mathrm{C}$, respectively). When the correlation was calculated for MDR1 and MDR3, no correlation was observed for MDR1 (Fig. 4A) and a significant $(p<0.005)$ linear correlation was found for MDR3 (Fig. 4B).

A)

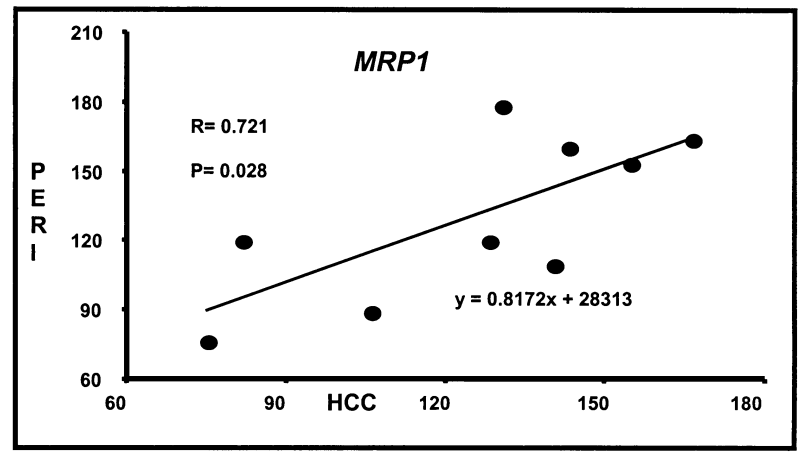

B)

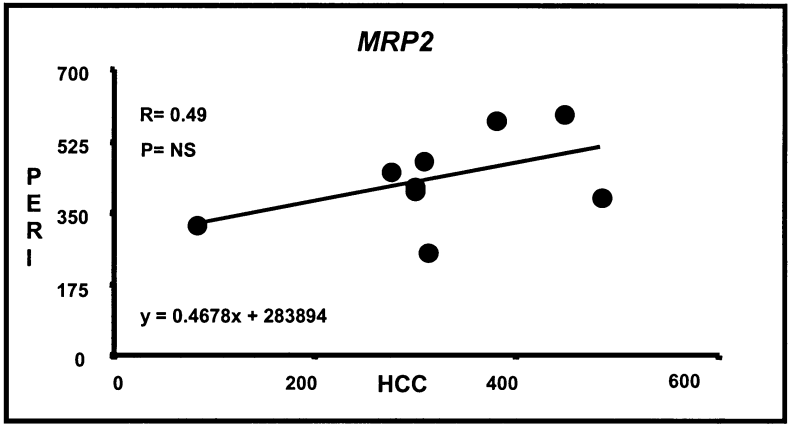

C)

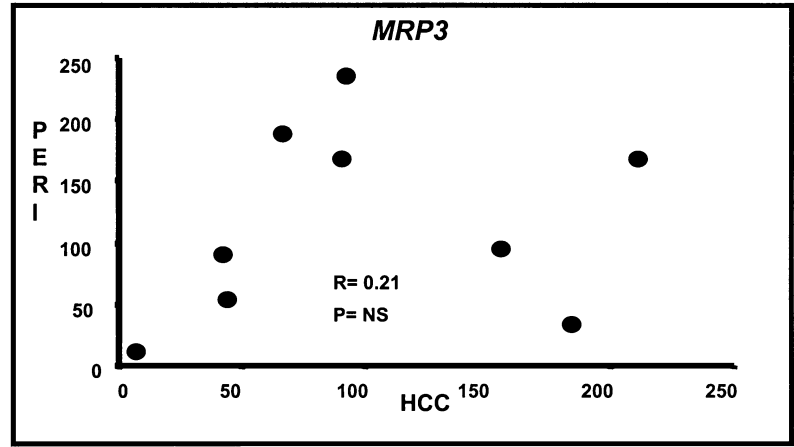

Fig. 3. Regression analysis for the analyzed ABCC transporters in neoplastic and perineoplastic tissue. (A) MRP1. (B) MRP2. (C) MRP3. A significant correlation was observed between the neoplastic and nonneoplastic tissue for MRP1 but not for MRP2 or MRP3. Values reported in $x$ and $y$ scales indicate $\operatorname{DLU}\left(\times 10^{3}\right)$. 
A)

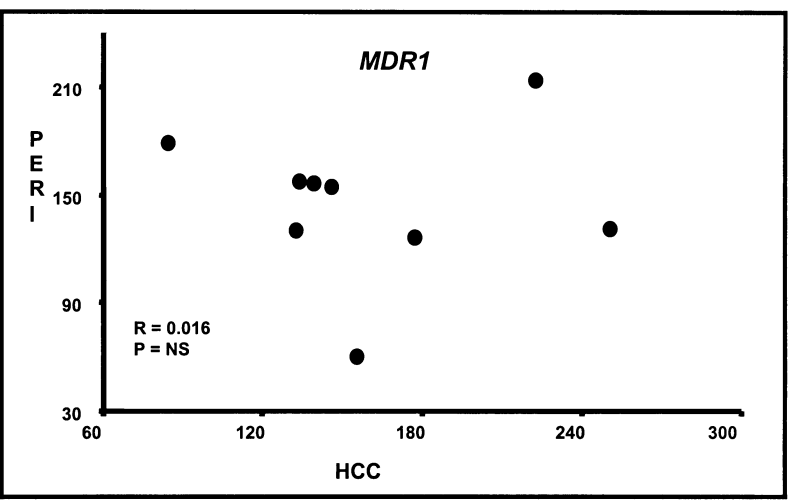

B)

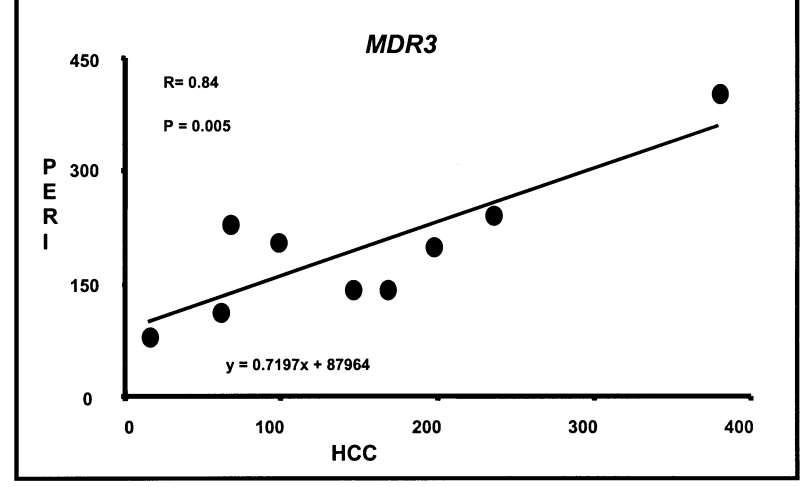

Fig. 4. Regression analysis for the analyzed $А В C B$ transporters in neoplastic and perineoplastic tissue. (A) MDR1. (B) MDR3. A significant correlation was observed between the neoplastic and nonneoplastic tissue for MDR3 but not for MDR1. Values reported in $x$ and $y$ scales indicate DLU $\left(\times 10^{3}\right)$.

\section{Discussion}

The possibility of the progression of chronic liver disease (cirrhosis) to HCC has been long recognized, although no clear data are available on the molecular events occurring during the neoplastic transformation. The importance of an early diagnosis of HCC during the natural history of cirrhosis has several important implications both in terms of prognosis and treatment. Small, monofocal HCC have been demonstrated to be more susceptible to treatment and to have a much better prognosis $(6,9)$. Therefore, understanding the molecular alterations is of particular importance, especially because of the finding that several antineoplastic drugs are transported into the liver cell and extruded from it via the composite family of $A B C$ proteins (24). In addition, several contrast mediaMRI in particular-are taken up by and excreted from the hepatocyte by members of the $A B C$ proteins $(25,26)$. The discovery of alteration in the expression of one or more of these transporters may end up in the design of specific MRI contrast agents targeted for neoplastic cells, thereby allowing early detection of this condition.

In this study we report on the difference in the expression of five genes encoding for $A B C B$ (MDR) and ABCC (MRP) transporters in liver neoplastic tissue and perineoplastic lesions as compared with cirrhosis, chronic cholestasis, and normal liver by using quantitative RT-PCR in formalin-fixed, paraffin-embedded tissues. The use of paraffin-embedded tissues has become increasingly important $(27,28)$. This method is also suitable for the detection of viral sequences in liver (29). The study of autoptic samples gives not only the possibility to use rather large amount of tissue but, most important in this case, allows the study of neoplastic and perineoplastic tissue at the same time in the same patient. A significant increment in the expression level of MRPI was found in HCC and perineoplastic tissue in all cases. Of interest is the observation that a significant correlation in MRP1 expression was found in neoplastic and perineoplastic tissue suggesting that the expression of this gene in neoplastic liver cells is associated with a similar overexpression in the nonneoplastic cells surrounding the lesion. Also, MRP2 expression was significantly increased in both tumor and perineoplastic lesions, but in contrast to what was observed with MRP1, the two phenomena are apparently not linked, as shown by the lack of correlation between the level of gene expression in the two tissues. Collectively, these findings indicate that the expression of MRP1 and MRP2 during hepatic carcinogenesis are differently regulated. This conclusion is also supported by the finding that MRP1 expression was increased in 5 over 16 cases of cirrhosis $(31 \%)$, whereas that of MRP2 was within the normal range in all cases. We are not in the position to assesses whether the cases with higher expression of MRP1 were progressing to HCC due to the use of autoptic samples. This interesting question needs to be addressed in prospective series.

The comparable expression of MRP2 we observed in cholestatic and in control liver fits with data reported in fresh tissue during chronic reduction of bile flow due to primary biliary cirrhosis or inflammation (30). Because the (cause) or better "origin" of cholestasis we investigated was extrahepatic neoplastic obstruction of the bile ducts, the comparable behavior of MRP2 expression found in the two studies suggest that a reduction of bile flow, due to any cause, is not associated to an altered gene expression of this canalicular transporter.

The mean value of MRP3 expression in both HCC and perineoplastic samples was significantly higher than cirrhosis and cholestasis even if largely scattered as a value within the normal range was found in two-thirds of the cases. The lack of increment in the expression of MRP3 is somehow different from that reported by Nies et al. (31), who found a net overexpression of this gene in human HCC. It is possible that this discrepancy may be related to different sampling procedures, the different etiology of the underlying chronic liver disease, or to previous treatment (chemotherapy) performed in some patients 
in that series. On the contrary, cirrhosis and cholestasis showed a particularly low MRP3 expression, which is in line with that reported in other types of non neoplastic cholestasis (30).

MDR1 expression was significantly increased both in HCC and perineoplastic tissues. We are not in the position to understand whether the increased gene expression may have a causative role or be an effect of tumor development. As suggested by Muller, the increased expression may be linked to cellular stress response, as demonstrated after UV irradiation and heat shock (32). Conversely, the gene overexpression may be directly connected with tumorogenesis; it has been reported that MDR1 expression confers a certain degree of resistance to apoptosis $(33,34)$. Interestingly, MDR1 expression was consistently low in both cirrhosis and cholestasis. Similar to what observed for MRP2 and MRP3, the overexpression of $M D R 1$ found in the tumor tissue was not linked to that observed in perineoplastic tissue, suggesting that the molecular events resulting in the increased expression of $M D R 1$ during neoplastic transformation differs from that taking place in the perineoplastic tissue. This is not the case for $M D R 3$ where, in spite of a gene expression similar to control, cirrhotic, and cholestatic conditions, a linear correlation was observed between the neoplastic and perineoplastic tissues. The lack of increment of $M D R 3$ in neoplastic tissue supports the conclusion that this $A B C$ protein is not directly involved in hepatic carcinogenesis.

Collectively, the gene expression of $5 \mathrm{ABC}$ proteins significantly varies according to the liver disease. An overexpression of MRP1, MRP2 and MDR1 was observed in both neoplastic and perineoplastic tissue, although comparable increment was found only for MRPI. On the contrary, the expression of these genes is not increased in other conditions affecting the liver cell such as cirrhosis and chronic cholestasis. The different behavior between HCC and cirrhosis particularly in the expression of MRP1, $M R P 2$, and MDR1 may help our understanding of whether the tissue may have undergone neoplastic transformation; an increased expression of these transporters may suggest neoplastic transformation. In addition, because $\mathrm{ABC}$ proteins are involved in the export of antineoplastic drugs and contrast agents from the cell, these findings may have important implications in the diagnosis and treatment of HCC observed during the natural history of liver cirrhosis.

\section{Acknowledgments}

This study was supported in part by grants from Fondo Studi Fegato-Onlus (FCRT00/01) and from an "in house research grant" of the University of Trieste. L.P. was supported in part by a career development award from Bracco SpA, Milan, Italy and from Fondo Studi Fegato-Onlus.

\section{References}

1. Bellentani S, Tiribelli C, Saccoccio G, et al. (1994) Prevalence of chronic liver disease in the general population of northern Italy: the Dionysos Study. Hepatology 20: 1442-1449.

2. Forns X, Ampurdanes S, Sanchez-Tapias JM, et al. (2001) Long-term follow-up of chronic hepatitis $\mathrm{C}$ in patients diagnosed at a tertiary-care center. J. Hepatol. 35: 265-271.

3. Bellentani S, Tiribelli C. (2001) The spectrum of liver disease in the general population: lesson from the Dionysos study. J. Hepatol. 35: 531-537.

4. Oka H, Kurioka N, Kim K, et al. (1990) Prospective study of early detection of hepatocellular carcinoma in patients with cirrhosis. Hepatology 12: 680-687.

5. Colombo M, de Franchis R, Del Ninno E, et al. (1991) Hepatocellular carcinoma in Italian patients with cirrhosis. $N$. Engl. J. Med. 325: 675-680.

6. Arii S, Yamaoka Y, Futagawa S, et al. (2000) Results of surgical and nonsurgical treatment for small-sized hepatocellular carcinomas: a retrospective and nationwide survey in Japan. The Liver Cancer Study Group of Japan. Hepatology 32: 1224-1229.

7. Bruix J, Llovet JM. (2002) Prognostic prediction and treatment strategy in hepatocellular carcinoma. Hepatology 35: 519-524.

8. Curley SA. (2001) Radiofrequency ablation of malignant liver tumors. Oncologist 6: 14-23.

9. Markovic S, Gadzijev E, Stabuc B, et al. (1998) Treatment options in Western hepatocellular carcinoma: a prospective study of 224 patients. J. Hepatol. 29: 650-659.

10. Schafer DF, Sorrell MF. (1999) Hepatocellular carcinoma. Lancet 353: 1253-1257.

11. Klein I, Sarkadi B, Varadi A. (1999) An inventory of the human ABC proteins. Biochim. Biophys. Acta 1461: 237-262.

12. Ambudkar SV, Dey S, Hrycyna CA, Ramachandra M, Pastan I, Gottesman MM. (1999) Biochemical, cellular, and pharmacological aspects of the multidrug transporter. Annu. Rev. Pharmacol. Toxicol. 39: 361-398.

13. Cole SP, Bhardwaj G, Gerlach JH, et al. (1992) Overexpression of a transporter gene in a multidrug-resistant human lung cancer cell line. Science 258: 1650-1654.

14. Hipfner DR, Deeley RG, Cole SP. (1999) Structural, mechanistic and clinical aspects of MRP1. Biochim. Biophys. Acta. 1461: 359-376.

15. Meijer GA, Schroeijers AB, Flens MJ, et al. (1999) Increased expression of multidrug resistance related proteins Pgp, MRP1, and LRP/MVP occurs early in colorectal carcinogenesis. J. Clin. Pathol. 52: 450-454.

16. Kullak-Ublick GA, Beuers U, Paumgartner G. (2000) Hepatobiliary transport. J. Hepatol. 32: 3-18.

17. Paulusma CC, Bosma PJ, Zaman GJ, et al. (1996) Congenital jaundice in rats with a mutation in a multidrug resistanceassociated protein gene. Science 271: 1126-1128.

18. Hooiveld GJ, van Montfoort JE, Meijer DK, Muller M. (2000) Function and regulation of ATP-binding cassette transport proteins involved in hepatobiliary transport. Eur. J. Pharm. Sci. 12: $13-30$.

19. Bellentani S, Saccoccio G, Costa G, et al. (1997) Drinking habits as cofactors of risk for alcohol induced liver damage. The Dionysos Study Group. Gut 41: 845-850.

20. Stanta G, Schneider C. (1991) RNA extracted from paraffinembedded human tissues is amenable to analysis by PCR amplification. Biotechniques 11: 304, 306, 308.

21. Stanta G, Bonin S, Perin R. (1998) RNA extraction from formalin-fixed and paraffin-embedded tissues. In Rapley DLM (ed). Methods in Molecular Biology: RNA Isolation and Characterization Protocols, 86th ed. Totowa, NY: Humana Press; 23-26.

22. Stanta G, Bonin S. (1998) RNA quantitative analysis from fixed and paraffin-embedded tissues: membrane hybridization and capillary electrophoresis. Biotechniques 24: 271-276.

23. Stanta G, Bonin S, Utrera R. (1998) RNA quantitative analysis from fixed and paraffin embedded tissues. In Rapley DLM (ed). Methods in Molecular Biology: RNA Isolation and Characterization Protocols, 86th ed. Totowa, NY: Humana Press; 113-119. 
24. Leslie EM, Deeley RG, Cole SP. (2001) Toxicological relevance of the multidrug resistance protein 1, MRPl (ABCC1) and related transporters. Toxicology 167: 3-23.

25. Pascolo L, Cupelli F, Anelli PL, et al. (1999) Molecular mechanisms for the hepatic uptake of magnetic resonance imaging contrast agents. Biochem. Biophys. Res. Commun. 257: 746-752.

26. Pascolo L, Petrovic S, Cupelli F, et al. (2001) Abc protein transport of MRI contrast agents in canalicular rat liver plasma vesicles and yeast vacuoles. Biochem. Biophys. Res. Commun. 282: 60-66.

27. Lehmann U, Kreipe H. (2001) Real-time PCR analysis of DNA and RNA extracted from formalin-fixed and paraffinembedded biopsies. Methods 25: 409-418.

28. Godfrey TE, Kim SH, Chavira M, et al. (2000) Quantitative mRNA expression analysis from formalin-fixed, paraffinembedded tissues using $5^{\prime}$ nuclease quantitative reverse transcription- polymerase chain reaction. J. Mol. Diagn. 2: 84-91.

29. Stanta G, Croce LS, Bonin S, Tisminetzky SG, Baralle FE, Tiribelli C. (2000) Cohort effect of HCV infection in liver cirrhosis assessed by a 25 year study. J. Clin. Virol. 17: 51-56.

30. Zollner G, Fickert P, Zenz R, et al. (2001) Hepatobiliary transporter expression in percutaneous liver biopsies of patients with cholestatic liver diseases. Hepatology 33: 633-646.

31. Nies AT, Konig J, Pfannschmidt M, Klar E, Hofmann WJ, Keppler D. (2001) Expression of the multidrug resistance proteins MRP2 and MRP3 in human hepatocellular carcinoma. Int. J. Cancer 94: 492-499.

32. Muller M. (2000) Transcriptional control of hepatocanalicular transporter gene expression. Semin. Liver Dis. 20: 323-337.

33. Thevenod F, Friedmann JM, Katsen AD, Hauser IA. (2000) Up-regulation of multidrug resistance P-glycoprotein via nuclear factor- kappaB activation protects kidney proximal tubule cells from cadmium- and reactive oxygen speciesinduced apoptosis. J. Biol. Chem. 275: 1887-1896.

34. Bunting KD, Zhou S, Lu T, Sorrentino BP. (2000) Enforced P-glycoprotein pump function in murine bone marrow cells results in expansion of side population stem cells in vitro and repopulating cells in vivo. Blood 96: 902-909. 